\title{
Effect of $n-3$ and $n-6$ unsaturated fatty acids on prostate cancer (PC-3) and prostate epithelial (RWPE-1) cells in vitro
}

Hongzhou Meng ${ }^{1}$, Yuzhen Shen ${ }^{2}$, Junhui Shen ${ }^{3}$, Feng Zhou ${ }^{2}$, Shengrong Shen ${ }^{2 *}$ and Undurti N Das ${ }^{4,5,6^{*}}$

\begin{abstract}
Prostate cancer (PCa) is one of the leading causes of death in the elderly men. Polyunsaturated fatty acids (PUFAs) regulate proliferation of cancer cells. In the present study, we evaluated the effect of various PUFAs on the proliferation and survival of human prostate cancer (PC-3) and human prostate epithelial (RWPE-1) cells in vitro. LA, GLA, AA, ALA, EPA and DHA (linoleic acid, gamma-linolenic acid, arachidonic acid, alpha-linolenic acid, eicosapentaenoic acid and docosahexaenoic acid respectively) when tested at 50, 100, 150, and $200 \mu \mathrm{M}$ inhibited proliferation of RWPE-1 and PC-3 cells, except that lower concentrations of LA (25 $\mu \mathrm{M})$ and GLA $(5,10 \mu \mathrm{M})$ promoted proliferation. Though all fatty acids tested produced changes in the production of interleukin-6 (IL-6), tumor necrosis factor-a (TNF-a), lipoxin $A_{4}$ and free radical generation by RWPE-1 and PC-3 cells, there were significant differences in their ability to do so. As expected, supplementation of various $n-3$ and n- 6 fatty acids to RWPE- 1 and PC-3 cells enhanced the content of the added fatty acids and their long-chain metabolites in these cells. In contrast to previous results, we did not find any direct correlation between inhibition of cell proliferation induced by various fatty acids and free radical generation. These results suggest that polyunsaturated fatty acids suppress proliferation of normal and tumor cells by a variety of mechanisms that may partly depend on the type(s) of cell(s) being tested and the way these fatty acids are handled by the cells. Hence, it is suggested that more deeper and comprehensive studies are needed to understand the actions of fatty acids on the growth of normal and tumor cells.
\end{abstract}

Keywords: n-6 Polyunsaturated fatty acids, n-3 Polyunsaturated fatty acids, Prostate cancer, Cytokines, Free radicals, Lipid peroxidation, Lipoxin A4

\section{Introduction}

Prostate cancer is one of the leading causes of cancer death among men in the United States [1]. Prostate cancer mortality rates are especially high in Northern Europe and Northern America and much lower in Asian countries [2,3]. Furthermore, immigrates from Asian countries have a significant increase in the risk of developing prostate cancer after residence in America [4], which suggests that, perhaps, western diets contribute to the development and progression of prostate cancer [5].

\footnotetext{
* Correspondence: shrshen@zju.edu.cn; undurti@hotmail.com ${ }^{2}$ Department of Food Science and Nutrition, School of Biosystems Engineering \& Food Science, Zhejiang University, Hangzhou 310058, China ${ }^{4}$ UND Life Sciences, 2020 S 360th St, K-202, Federal Way, WA 98003, USA Full list of author information is available at the end of the article
}

Compared to Eastern diet, Western diet contains higher levels of saturated fats, which may play a role in prostate cancer development [6]. The role of dietary fats on the risk of prostate cancer is controversial [7]. South American studies showed that only $\alpha$-linolenic acid influenced the progression of prostate cancer. Several studies reported that n-3 PUFAs have an inverse association with prostate cancer, which showed that EPA and DHA suppressed human prostate tumor cell growth. This could be related to the fact that EPA and DHA can displace AA from cell membrane phospholipids and suppress pro-inflammatory prostaglandin synthesis [8]. However, findings from other studies have been inconsistent, some of which found positive association but others found weak association between unsaturated fatty acid intake and prostate cancer. In view of these conflicting results, we performed a detailed study

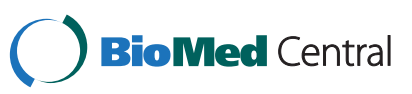


on the effect of various unsaturated fatty acids on the growth of prostate cancer cells in vitro and the mechanisms involved therein.

Experimental studies showed that n-3 PUFAs such as EPA and DHA that are derived from essential fatty acid (EFA) ALA can suppress the growth of prostate cancer cells, whereas n-6 PUFAs such as GLA and AA, which are derived from EFA LA promote prostate tumor carcinogenesis $[9,10]$. Epidemiological studies were inconclusive on the association between prostate cancer risk and intake of $n-3$ or $n-6$ PUFAs that are substrates for eicosanoid synthesis, with n-6 PUFAs being converted predominantly into pro-inflammatory eicosanoids, while n-3 PUFAs being converted into anti-inflammatory or less pro-inflammatory eicosanoids [11]. There is increasing evidence that lipid metabolism plays an important role in various cellular processes, including cell proliferation, apoptosis, motility and inflammatory responses that may contribute to different aspects of tumorigenesis $[12,13]$.

Tumor necrosis factor (TNF)- $\alpha$ can behave both as a pro-apoptotic factor and also a survival factor of tumor cells. Tumor cells themselves and the surrounding normal cells have the ability to secrete TNF- $\alpha$ that is a strong promoter of interleukin (IL)-6, another cytokine, that influences ERK/MAPK signaling pathway and thus, may show anti-proliferative and pro-apoptotic effect in PC-3 cell [14]. IL-6 is a pleiotropic cytokine regulating gene expression and interacting with B-cell and T-cell, and secreted by both hormone-dependent (LNCaP) and hormone-refractory (DU-145, PC-3) cells [15]. IL-6 may induce the development of melanoma, renal cell carcinoma, ovarian carcinoma, multiple myeloma, prostate carcinoma and breast cancer [16]. This implies that resolution of inflammation may lead to regression of cancer. In this context, it is noteworthy that AA, EPA and DHA form precursors to anti-inflammatory and pro-resolution modulators such as lipoxins, resolvins and protectins that may contribute to resolution of inflammation and thus, aid in the regression of tumor $[17,18]$.

In addition, free radicals generated during cellular respiration and normal metabolism also have a modulatory influence on tumor cell growth. Free radicals when generated in excess damage DNA that, in turn, may initiate the development of cancer. PUFAs being highly unsaturated are easily targeted by free radicals to generate lipid peroxides that are toxic to cells. Both free radicals and lipid peroxides may serve as double edged sword: when produced in normal cells damage DNA and initiate the carcinogenic process; but when produced in sufficient amounts in tumor cells may actually kill tumor cells in view of their cytotoxic properties [19-22]. Thus, the role of PUFAs and their metabolites in cancer may depend on the way they are handled by normal and tumor cells.
In order to understand the role of various PUFAs on the growth of normal and tumor cells, we studied the effect of various PUFAs: LA, GLA, AA, ALA, EPA and DHA on the growth of RWPE-1(human prostate epithelial cell) and PC-3 (human prostatic carcinoma cell) and their effects on fatty acid metabolism and ability to modulate the production of IL-6, TNF- $\alpha$, lipoxin $\mathrm{A}_{4}$ and free radical generation and the results are reported here.

\section{Materials and methods Materials}

ALA, LA, GLA, AA, EPA and DHA were purchased from Sigma (USA). $20 \mathrm{mmol} / \mathrm{l}$ stock solutions of both ALA and LA were prepared in $0.1 \mathrm{~mol} / \mathrm{l} \mathrm{NaOH}$ respectively, and then further diluted in sterile water until the concentrations to be used in the experiments was obtained, whereas $20 \mathrm{mmol} / \mathrm{l}$ stock solutions of GLA, AA, EPA, DHA were prepared in anhydrous ethanol and further diluted in RPMI 1640 medium (GIBCO) until the concentrations needed to be used in the experiments was reached.

\section{Cell culture}

Human prostatic carcinoma (PC-3) cell line and human prostate epithelial (RWPE-1) cell line were purchased from Institute of Biochemistry and Cell Biology, Chinese Academy of Sciences (Shanghai, China). Cells were grown in RPMI 1640 medium (GIBCO) supplemented with $100 \mathrm{U} / \mathrm{ml}$ penicillin, $100 \mathrm{U} / \mathrm{ml}$ streptomycin and $10 \%$ fetal bovine serum and grown $37^{\circ} \mathrm{C}$ in humidified air containing $5 \% \mathrm{CO}_{2}$. The culture medium was replaced every 3 days.

\section{Cell proliferation assays}

MTT(3-[4,5-dimethythiazol-2-yl]-2,5- diphenyltetrazolium bromide) assay was used for the determination of the number of viable cells in cell proliferation assays [23]. Both PC-3 and RWPE-1 cells were plated in 96-well plates with a volume of $190 \mu \mathrm{l}$ at a density of $5 \times 104 \mathrm{cells} / \mathrm{ml}$. The cells were incubated with different concentrations of LA, GLA, AA, ALA, EPA and DHA for 24, 48, $72 \mathrm{~h}$. At the end of incubation period, medium was removed and $20 \mu \mathrm{L}$ of $5 \mathrm{mg} / \mathrm{ml}$ MTT was added to each well, incubated for 4 hours at $37^{\circ} \mathrm{C}$ and optical densities were read by a microplate reader at $490 \mathrm{~nm}$.

\section{Lipoxin $\mathrm{A}_{4}$ measurement}

The production of $\mathrm{LXA}_{4}$ in cell culture supernatant was measured by ELISA kit [24]. Both PC-3 cells and RWPE-1 cells were inoculated in 6-well plates in a volume of $3 \mathrm{ml}$ at a density of $1 \times 10^{5}$ cells $/ \mathrm{ml}$ and incubated for $24 \mathrm{~h}$. The supernatant of the cells (PC-3 and RWPE-1) that were treated with different concentrations of various fatty acids (LA: 50, $150 \mu \mathrm{M}$; GLA: $25,50,75 \mu \mathrm{M}$; 
AA:50, $100 \mu \mathrm{M}$; ALA:50, $150 \mu \mathrm{M}$; EPA:50, $100 \mu \mathrm{M}$ and DHA: $50,100 \mu \mathrm{M})$ for $48 \mathrm{~h}$ was collected for the measurement of lipoxin A4 and was quantified using $\mathrm{LXA}_{4}$ ELISA kit according to the manufacturer's specifications (Source Leaf Biological Technology, Shanghai, China).

\section{IL-6 and TNF- $a$ production}

Cells were seeded in 6-well plates in a volume of $3 \mathrm{ml}$ at a density of $1 \times 10^{5}$ cells/ml (PC-3 and RWPE-1) and incubated for $24 \mathrm{~h}$ before treatment. Cells were then incubated with the indicated concentrations of various PUFAs (LA: 50, $150 \mu \mathrm{M}$;GLA:25, 50, $75 \mu \mathrm{M}$; AA:50, $100 \mu \mathrm{M}$, ALA:50, $150 \mu \mathrm{M}$, EPA:50, $100 \mu \mathrm{M}$ and DHA:50, $100 \mu \mathrm{M}$ ) for $48 \mathrm{~h}$, at the end of which the culture supernatant was collected for the estimation of IL- 6 and TNF- $\alpha$ content using respective ELISA kits according to the manufacturer's instructions (Boster, China).

Determination of free fatty acids by gas chromatography (GC) Both PC-3 and RWPE-1 cells were inoculated in $50 \mathrm{ml}$ cell culture flasks in a volume of $6 \mathrm{ml}$ at a density of $1 \times 10^{5}$ cells $/ \mathrm{ml}$ respectively and cultured for $24 \mathrm{~h}$. Then the cells were treated with selected concentrations of LA: 50, $150 \mu \mathrm{M}$; GLA: 25, 50, $75 \mu \mathrm{M}$; AA: 50, $100 \mu \mathrm{M}$; ALA: 50, $150 \mu \mathrm{M}$; EPA: 50, $100 \mu \mathrm{M}$; and DHA: $50,100 \mu \mathrm{M}$; for $48 \mathrm{~h}$. At the end of the incubation period, cells were harvested by centrifuging at 2,000 rpm for 4 min and washed twice with PBS and finally re-suspended in $500 \mu \mathrm{l} \mathrm{PBS}$ The cell suspension was extracted with $1 \mathrm{ml} \mathrm{HCl}$-methanol ( $\mathrm{v}: \mathrm{v}=5 \%$ ) and the tubes were sealed and heated in incubator at $100^{\circ} \mathrm{C}$ for $3 \mathrm{~h}$ [25]. After cooling to the room temperature, $1 \mathrm{ml}$ of highpurity water was added and the methyl esters were extracted with $3 \mathrm{ml}$ of $\mathrm{n}$-hexane in 3 portions. The $\mathrm{n}$-hexane phase was collected together and transferred to another tube and diluted with the same volume of highpurity water for washing following which $n$-hexane phase was filtered with $0.22 \mu \mathrm{m}$ filter membrane and transferred to another tube. The extract was evaporated under nitrogen and the residue redissolved in $100 \mu \mathrm{ln}$-hexane.

\section{Gas chromatography analysis}

The methylated fatty acids in the cells were analysed using a $60 \mathrm{~m}$ non-polar capillary column $(0.25 \mathrm{~mm}$ internal diameter, DB-23, Agilent, America) on an Agilent 7890A gas chromatograph fitted with a flame ionization detector (FID). $1 \mu \mathrm{L}$ samples were injected in non-spilt mode (injector temperature: $250^{\circ} \mathrm{C}$ ). Column temperature was held at $130^{\circ} \mathrm{C}$ for $1 \mathrm{~min}$, and increased at a rate of $6.5^{\circ} \mathrm{C} / \mathrm{min}$ to $170^{\circ} \mathrm{C}$, then increased at a rate of $2.75^{\circ} \mathrm{C} / \mathrm{min}$ to $225^{\circ} \mathrm{C}$ which was maintained for $10 \mathrm{~min}$. Fatty acids were quantified by an external standard method using the animal fatty acid methyl ester mix (FAME Mix, Supelco).
Detection of free radicals by Electron Spin Resonance (ESR) The Preparation of Spin Trapping Agent PBN

The PBN needed was weighed accurately and dissolved in sterile PBS in warm bath. Then it was stirred for 30 min until dissolved completely to become PBN saturated solution with the concentration of $200 \mathrm{mmol} / \mathrm{l}$, and saturated solution was diluted with the same volume of RPMI 1640 when used. PBN stock solutions were filtered with $0.22 \mu \mathrm{m}$ filter membrane.

\section{Trapping radicals from cells and preparation of samples for Electron Spin Resonance (ESR)}

Cells were planted in 12-well plates in a volume of $2 \mathrm{ml}$ at a density of $1 \times 10^{5}$ cells/ml (PC-3 and RWPE- 1 ) and incubated for $24 \mathrm{~h}$ before the treatment. Then both PC-3 and RWPE-1 cells were exposed to selected concentrations of LA (50, $150 \mu \mathrm{M})$; GLA $(25,50,75 \mu \mathrm{M})$; AA (50, $100 \mu \mathrm{M})$; ALA (50, $150 \mu \mathrm{M})$; EPA (50, $100 \mu \mathrm{M})$; and DHA $(50,100 \mu \mathrm{M})$ for $48 \mathrm{~h}$ respectively. At the end of 48 hours of treatment, the medium was removed and $0.5 \mathrm{ml}$ RPMI 1640 medium without fetal bovine serum was added to each well, together with $0.5 \mathrm{ml} \mathrm{PBN}$ at the final concentration of $100 \mathrm{mmol} / \mathrm{l}$ in each group. The cells were incubated in $37^{\circ} \mathrm{C}$ for $45 \mathrm{~min}$, and then scraped with sterile cell scrapers. Cell suspensions were collected into $1.5 \mathrm{ml}$ centrifuge tubes and the samples were detected using ESR Spectrometer (Bruker, A300) as soon as possible.

Conditions used for detection: $\mathrm{X}$ waveband, Center Magnetic Field: 3385G, Sweep Length: 400G, Modulation Amplitude: 3.2G, Microwave Power: $20 \mathrm{~mW}$, at room temperature.

\section{Statistical analysis}

All results obtained were expressed in mean \pm SD. Statistical analysis was performed by analysis of variance or by paired t-test when just two values were compared, using SPSS software version 16.0. Each experiment was carried out in triplicate and repeated twice. Group differences were shown as * meaning $\mathrm{p}<0.05$, * meaning $\mathrm{p}<0.01$, w** meaning $\mathrm{p}<0.001$.

\section{Results}

\section{Cell proliferation and viability}

Supplementation of various fatty acids AA $(25,50,75,100$, $125,150,175 \mu \mathrm{M})$, ALA $(50,100,150,160,180,200,220$, $240 \mu \mathrm{M})$, EPA $(25,50,75,100,125,150,175 \mu \mathrm{M})$, DHA $(25,50,75,100,125,150,175 \mu \mathrm{M})$ to RWPE-1 and PC-3 cells resulted in a significant decrease in cell viability when compared with the control group. Both RWPE-1 and $\mathrm{PC}-3$ cells showed no significant decrease in cell proliferation at lower concentrations of both LA (below $50 \mu \mathrm{M}$ ) and GLA (below $50 \mu \mathrm{M}$ ), while the growth of RWPE-1 cells were suppressed notably at higher concentrations of LA $(100,150,200 \mu \mathrm{M})$ and GLA 
$(75,100,125,150,175 \mu \mathrm{M})$, and the proliferation of PC-3 cells were suppressed at LA $(150,200 \mu \mathrm{M})$ and GLA $(100,125,150,175 \mu \mathrm{M})$ (Figures 1, 2, 3, 4, 5 and 6) which suggested that RWPE-1 cells are more sensitive to the cytotoxic action of fatty acids compared to PC-3 cells.

Fatty acid composition of RWPE1 and PC-3 cells

The fatty acid profiles of RWPE-1 and PC-3 cells were significantly different as shown in Tables 1 and 2 and Figures 7, 8. RWPE-1 cells have significantly higher amounts of LA, ALA, EPA, and DHA compared to PC-3 cells (see Tables 1 and 2 and 3 ).

More than $50 \%$ of total fatty acids in RWPE- 1 and PC-3 cells in the control groups and treated with LA, AA, ALA, EPA and DHA were saturated and monounsaturated fatty acids, except for RWPE-1 and PC-3 cells that were supplemented with $75 \mu \mathrm{M}$ GLA, which contained higher content of n-6 PUFAs (56.41\% in RWPE-1, 38.72\% in PC-3 cells) (Figures 7 and 8). On the other hand, n-3 PUFAs content in both RWPE-1and PC-3 cells that were treated with $100 \mu \mathrm{M}$ AA was $~ 20.72 \%$ and $33.73 \%$ respectively In contrast, the content of n-3 PUFAs in RWPE-1 cells incubated with $150 \mu \mathrm{M}$ LA were at the lowest level (2.6\%), and RWPE-1 cells treated with ALA (50, $150 \mu \mathrm{M})$ had the lowest contents (approx. $2.79 \%$ and $2.80 \%$, respectively) of n-6 PUFAs.

RWPE-1 cells supplemented with n-6 PUFAs (50 $\mu \mathrm{M}$ AA and $100 \mu \mathrm{M}$ AA; $25 \mu \mathrm{M}$ GLA, $50 \mu \mathrm{M}$ GLA and $75 \mu \mathrm{M}$ GLA) resulted in $0.48,6.31,5.21,10.03,29.85 \%$ increases for the sum of n-6 PUFAs and 3.54, 12.90, $2.74,9.00,1.52 \%$ increases for the sum of $n-3$ PUFAs compared to control. However, supplementation with LA (50 and $150 \mu \mathrm{M}$ ) resulted in 21.82, 21.72\% increase in the total amount of n-6 PUFAs and 1.50, 5.17\% decrease in

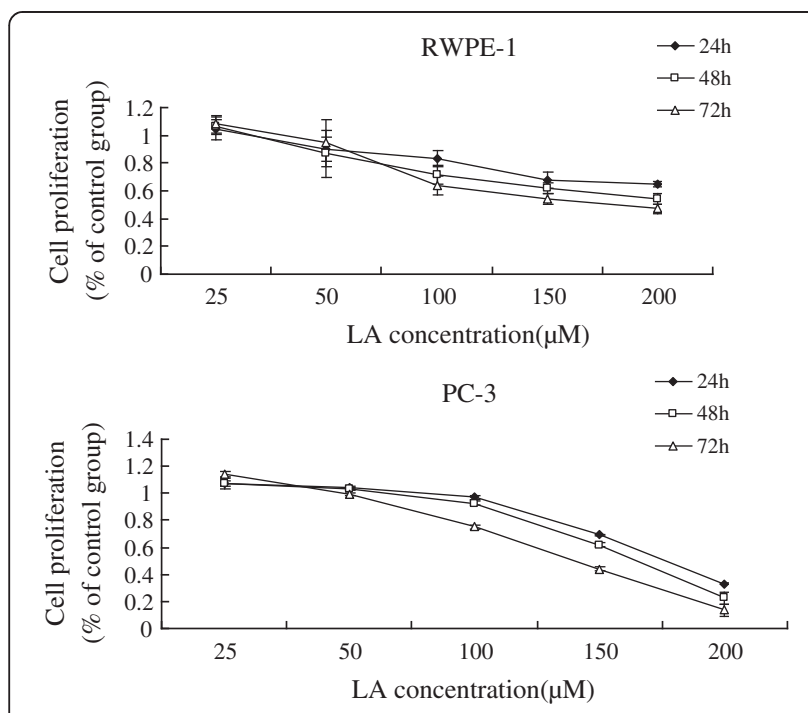

Figure 1 Effect of different doses of LA on the growth of RWPE-1 and PC-3 cells in vitro at 24,48 and 72 hours.

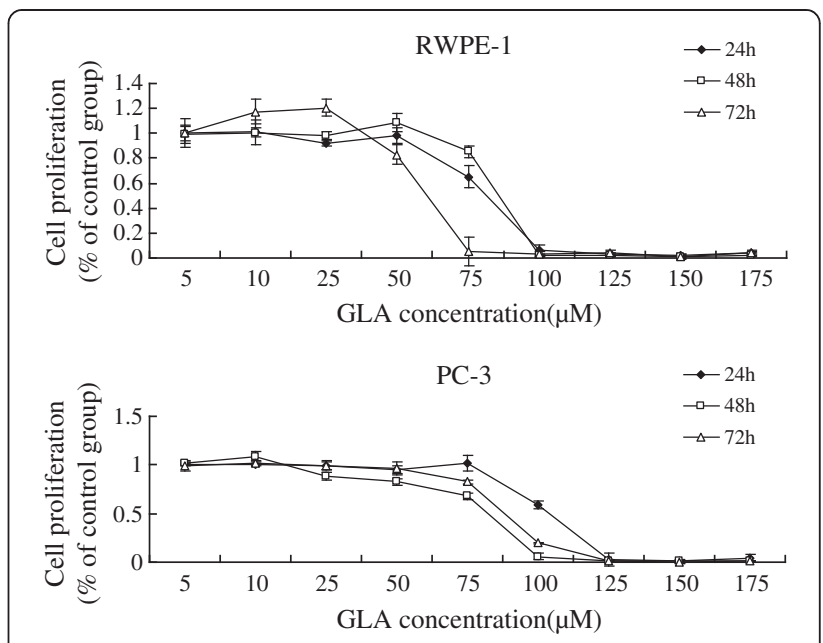

Figure 2 Effect of different doses of GLA on the growth of RWPE-1 and PC- 3 cells in vitro at 24,48 and 72 hours.

n-3 PUFAs compared to control. In contrast, supplementation with n-3 PUFAs $(50 \mu \mathrm{M}$ ALA and $150 \mu \mathrm{M}$ ALA; $50 \mu \mathrm{M}$ EPA and $100 \mu \mathrm{M}$ EPA; $50 \mu \mathrm{M}$ DHA and $100 \mu \mathrm{M}$ DHA) to RWPE-1 cells resulted in 23.76, 23.75, $16.87,20.36,21.6613 .52 \%$ decrease in the total amount of n-6 PUFAs in comparison with control. In contrast, supplementation of $50 \mu \mathrm{M}$ ALA, $150 \mu \mathrm{M}$ ALA, and $100 \mu \mathrm{M}$ EPA resulted in 1.20, 3.68, 6.01\% decrease, while supplementation with $50 \mu \mathrm{M}$ EPA, $50 \mu \mathrm{M}$ DHA, $100 \mu \mathrm{M}$ DHA resulted in 1.87, 3.47, 0.85\% increase in n-3 PUFAs above control (see Figures 7 and 8; Tables 1, 2 and 3).

On the other hand, PC-3 cells that were supplemented with n-6 PUFAs $(50 \mu \mathrm{M}$ LA; $50 \mu \mathrm{M}$ AA; and $100 \mu \mathrm{M}$ AA) resulted in a marginal decrease of $\sim 0.38,3.69$, $4.08 \%$ in the total amount of n-6 PUFAs and 3.99, 15.70,

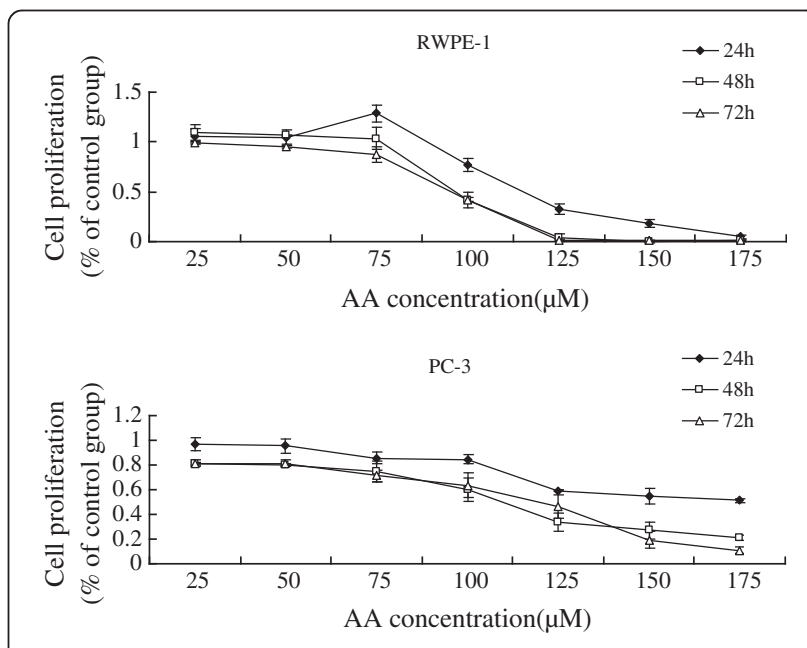

Figure 3 Effect of different doses of AA on the growth of RWPE-1 and PC-3 cells in vitro at 24,48 and 72 hours. 


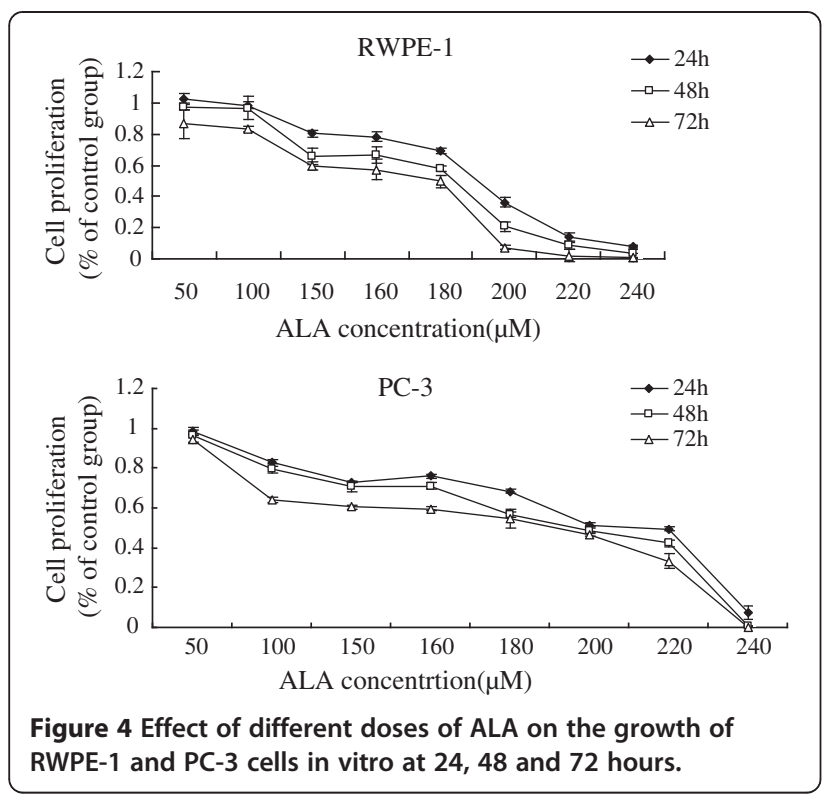

24.49\% increase in n-3 PUFAs in comparison to control. Supplementation with $25 \mu \mathrm{M}$ GLA, $50 \mu \mathrm{M}$ GLA and $75 \mu \mathrm{M}$ GLA resulted in an increase in the total content of n-6 PUFAs by $15.32,6.60,27.54 \%$ respectively and n-3 PUFAs by $1.71,13.30$, and $11.64 \%$ respectively above the control values. In contrast, PC-3 cells supplemented with LA $(50 \mu \mathrm{M})$ resulted in 7.72 and $4.68 \%$ decrease in the total amount of n-6 and n-3 PUFAs respectively compared to control groups. Supplementation of n-3 PUFAs $(50 \mu \mathrm{M}$ ALA and $150 \mu \mathrm{M}$ ALA; $50 \mu \mathrm{M}$ EPA and $100 \mu \mathrm{M} \mathrm{EPA)} \mathrm{decreased} \mathrm{the} \mathrm{percentages}$ of the sum of $n-6$ PUFAs by $6.76,6.44,3.87,2.46 \%$ and the sum of $n-3$ PUFAs by a very small amount $(0.52,1.67$, $4.82,2.87 \%$ respectively), while supplementation with DHA (50 and $100 \mu \mathrm{M}$ ) decreased the total amount of $\mathrm{n}-6$

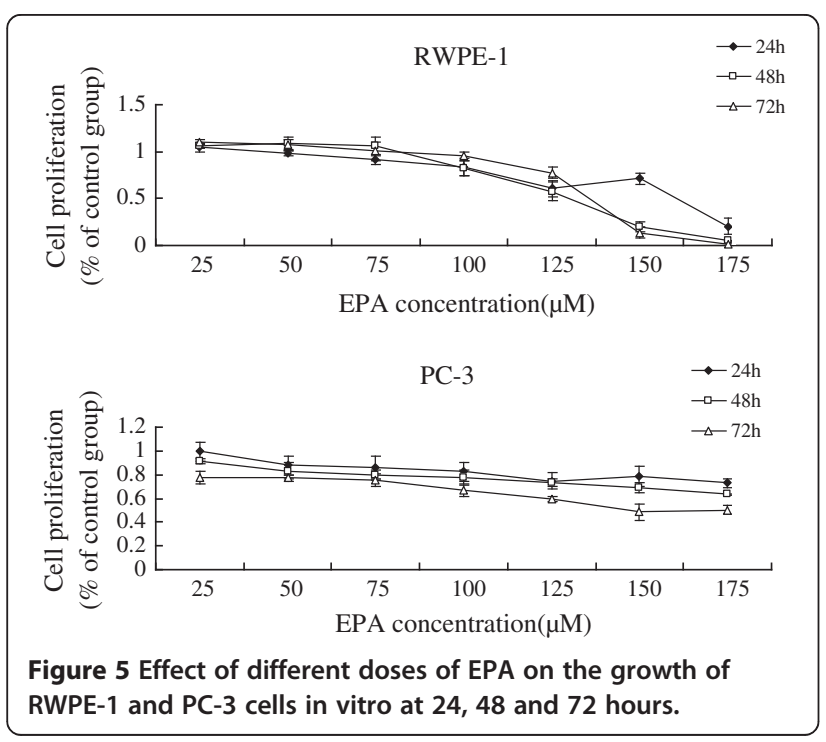

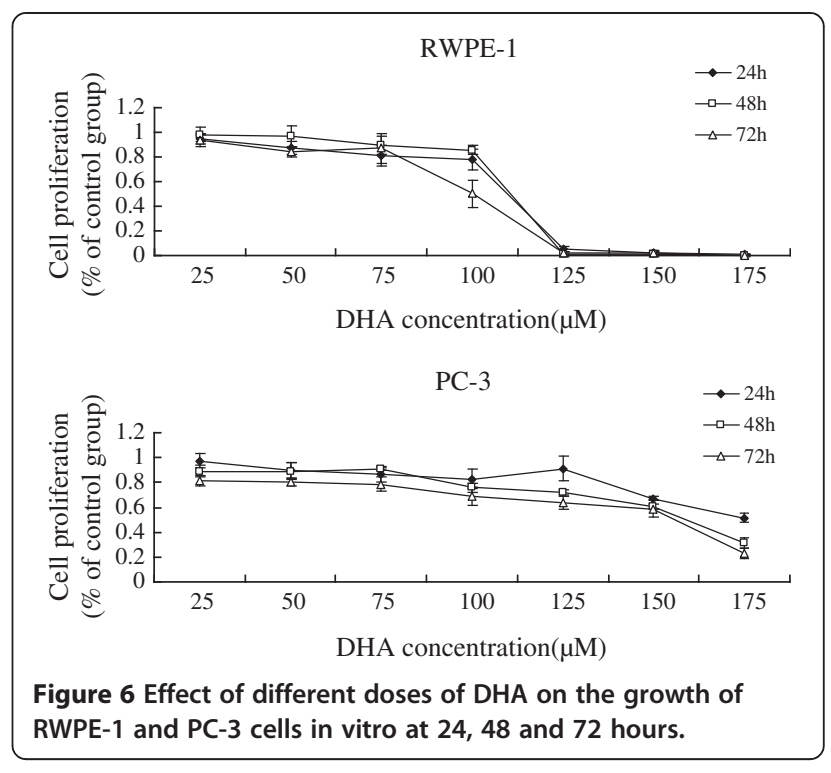

PUFAs by $3.20,4.56 \%$ and increased the levels of $n-3$ PUFAs by $13.08,23.66 \%$ respectively (see Figures 7 and 8; Tables 1, 2 and 3).

Addition of LA, GLA, AA, ALA, EPA and DHA to RWPE-1 and PC-3 cells resulted in significant changes in their content of the respective fatty acids as shown in Tables 1, 2 and 3. For instance, RWPE-1 cells, when supplemented with $150 \mu \mathrm{M}$ LA, $75 \mu \mathrm{M}$ GLA and $150 \mu \mathrm{M}$ AA resulted in an increase in its LA, GLA and AA content in the cells by 1.37, 17.63 and 11.17-fold respectively. Similarly, supplementation with $150 \mu \mathrm{M}$ of ALA, $100 \mu \mathrm{M}$ of EPA and $100 \mu \mathrm{M}$ of DHA enhanced their content of ALA, EPA and DHA by 1.83, 3.88 and 5.93-fold increase in the respective fatty acids' supplemented RWPE 1 cells (Table 3). PC-3 cells supplemented with LA $(150 \mu \mathrm{M})$, AA $(100 \mu \mathrm{M})$, ALA $(150 \mu \mathrm{M})$, EPA $(100 \mu \mathrm{M})$ and DHA $(100 \mu \mathrm{M})$ also showed 13.71, 18.2, 17.75, 5.64 and 26.87 -fold increase respectively in the content of these fatty acids (Table 3). Surprisingly, supplementation of GLA75 $\mu \mathrm{M}$ did not produce any significant increase in the GLA content of PC-3 cells but showed a significant increase in its AA content suggesting that possibly, GLA is converted to its long-chain metabolite AA (Table 2).

\section{Changes in IL-6, TNF- $a, \mathrm{LXA}_{4}$ and free radical generation}

IL- 6 , TNF- $\alpha$ and LXA $_{4}$ were detectable in the culture supernatant of both RWPE-1 and PC-3 cells with and without supplementation with LA $(50,150 \mu \mathrm{M})$, GLA $(25,50,75 \mu \mathrm{M})$, AA $(50,100 \mu \mathrm{M})$, ALA $(50,150 \mu \mathrm{M})$, EPA $(50,100 \mu \mathrm{M})$ and DHA $(50,100 \mu \mathrm{M})$ for $48 \mathrm{~h}$ (see Figures 9, 10, 11, 12, 13 and 14; and Tables 4, 5). Significant differences in the amount of IL-6, TNF- $\alpha$ and LXA $_{4}$ released by both RWPE- 1 and PC- 3 cells in the presence of LA, GLA, AA, ALA, EPA and DHA was noted in comparison to control. It is interesting to find that both 
Table 1 Fatty acid analysis of RWPE-1 cells that were supplemented with various fatty acids at the end of $\mathbf{4 8}$ hours of supplementation of various fatty acids

\begin{tabular}{|c|c|c|c|c|c|c|c|}
\hline \multirow{2}{*}{$\begin{array}{l}\text { Fatty acids } \\
\text { in RWPE-1 }\end{array}$} & \multicolumn{7}{|c|}{ Composition percentage (\%) } \\
\hline & Linolelaidic acid & Linoleic acid & $Y$-linolenic acid & Arachidonic acid & a-linolenic acid & EPA & DHA \\
\hline Control & $2.15 \pm 0.50$ & $0.38 \pm 0.09$ & $0.76 \pm 0.13$ & $0.92 \pm 0.14$ & $0.47 \pm 0.09$ & $0.86 \pm 0.13$ & $2.58 \pm 0.49$ \\
\hline $\mathrm{LA}(50 \mu \mathrm{M})$ & $0.12 \pm 0.05^{* * *}$ & $1.59 \pm 0.13^{* *}$ & $0.49 \pm 0.08^{*}$ & $1.76 \pm 0.39^{* *}$ & $0.19 \pm 0.02^{*}$ & $1.73 \pm 0.41^{*}$ & $2.60 \pm 0.60$ \\
\hline LA(150 $\mu \mathrm{M})$ & $0.18 \pm 0.08^{* * *}$ & $0.52 \pm 0.18^{*}$ & $2.62 \pm 0.64^{* *}$ & $0.70 \pm 0.12$ & $0.33 \pm 0.09$ & $0.78 \pm 0.14$ & $0.69 \pm 0.06^{* *}$ \\
\hline GLA(25 $\mu \mathrm{M})$ & $1.64 \pm 0.03^{*}$ & $0.19 \pm 0.03^{*}$ & $1.44 \pm 0.09^{*}$ & $21.95 \pm 2.99^{* * *}$ & $3.48 \pm 0.57^{* *}$ & N.D & $0.43 \pm 0.14^{* *}$ \\
\hline GLA(50 $\mu \mathrm{M})$ & $1.13 \pm 0.02^{* *}$ & $0.65 \pm 0.06^{*}$ & $1.01 \pm 0.13^{*}$ & $27.21 \pm 0.02^{* * *}$ & $8.45 \pm 0.19 * * *$ & N.D & $0.65 \pm 0.01^{* *}$ \\
\hline GLA(75 $\mu \mathrm{M})$ & N.D & $0.99 \pm 0.17^{*}$ & $12.34 \pm 0.55^{* * *}$ & $19.63 \pm 1.47^{* * *}$ & $10.59 \pm 1.42^{* * *}$ & N.D & $0.88 \pm 0.07^{* *}$ \\
\hline $\mathrm{AA}(50 \mu \mathrm{M})$ & $19.58 \pm 0.83^{* * *}$ & $7.3 \pm 0.19^{* *}$ & $4.57 \pm 1.45^{* *}$ & $7.01 \pm 0.74^{* *}$ & $0.69 \pm 0.27^{*}$ & $5.52 \pm 0.76^{* * *}$ & $6.63 \pm 0.17^{* *}$ \\
\hline $\mathrm{AA}(100 \mu \mathrm{M})$ & $21.22 \pm 0.29^{* * *}$ & $7.19 \pm 0.18^{* * *}$ & $4.04 \pm 1.10^{* *}$ & $10.28 \pm 0.43^{* * *}$ & $1.60 \pm 0.22^{* *}$ & $10.63 \pm 1.27^{* * *}$ & $9.30 \pm 1.68^{* *}$ \\
\hline ALA(50 $\mu \mathrm{M})$ & $0.56 \pm 0.08^{* * *}$ & $0.39 \pm 0.07$ & $0.97 \pm 020$ & $0.49 \pm 0.05^{*}$ & $0.62 \pm 0.13^{*}$ & $2.04 \pm 0.41^{*}$ & $2.60 \pm 0.64$ \\
\hline $\operatorname{ALA}(150 \mu \mathrm{M})$ & $0.17 \pm 0.07^{* * *}$ & $0.53 \pm 0.08$ & $0.77 \pm 0.23$ & $0.85 \pm 0.13$ & $0.86 \pm 0.10^{*}$ & $1.92 \pm 0.60^{* *}$ & $0.43 \pm 0.05^{* *}$ \\
\hline $\mathrm{EPA}(50 \mu \mathrm{M})$ & $0.92 \pm 0.02^{* *}$ & $4.67 \pm 0.59^{* * *}$ & $0.83 \pm 0.02$ & N.D & $2.61 \pm 0.84^{* *}$ & $1.14 \pm 0.25$ & $6.27 \pm 0.34^{* * *}$ \\
\hline $\mathrm{EPA}(100 \mu \mathrm{M})$ & $1.24 \pm 0.32^{* *}$ & $1.83 \pm 0.34^{* *}$ & $1.65 \pm 0.34^{*}$ & $1.07 \pm 0.04$ & $0.53 \pm 0.17$ & $4.42 \pm 0.43^{* * *}$ & $7.22 \pm 0.44^{* * *}$ \\
\hline $\mathrm{DHA}(50 \mu \mathrm{M})$ & $1.14 \pm 0.41^{* *}$ & $1.41 \pm 0.07^{* *}$ & $0.93 \pm 0.32$ & $2.94 \pm 0.59^{* *}$ & N.D & N.D & $14.95 \pm 0.63^{* * *}$ \\
\hline DHA $100 \mu \mathrm{M}$ & $1.54 \pm 0.09^{*}$ & $1.38 \pm 0.32^{* *}$ & $2.41 \pm 0.64^{* *}$ & $2.29 \pm 0.00^{* *}$ & $0.44 \pm 0.06$ & N.D & $15.35 \pm 0.08^{* * *}$ \\
\hline
\end{tabular}

${ }^{*} \mathrm{P}<0.05,{ }^{* * \mathrm{P}}<0.01,{ }^{* * *} \mathrm{P}<0.001$ compared to control.

RWPE-1 and PC-3 cells when supplemented with LA, GLA, AA, ALA, EPA and DHA resulted in the production of widely different levels of free radicals detected by ESR.

Supplementation with LA $(50,150 \mu \mathrm{M})$ for $48 \mathrm{~h}$, significantly lowered secretion of IL-6, TNF- $\alpha$ and LXA $_{4}$ by PC-3 cells when compared with control group (Figure 9 and Table 5). Production of free radicals changed little in contrast with PC-3 cells in other treatments (GLA, AA, ALA, EPA and DHA). Similarly, LA (50 and $150 \mu \mathrm{M})$ decreased the secretion of IL- 6 and LXA $_{4}$ but an increase in TNF- $\alpha$ was noted by RWPE-1 cells (Figure 9 and Table 4).

On the other hand, treatment with GLA resulted in a significant reduction in the secretion of IL-6, TNF- $\alpha$, $\mathrm{LXA}_{4}$ and free radicals by RWPE-1 cells (Figure 10),

Table 2 Fatty acid analysis of PC-3 cells that were supplemented with various fatty acids at the end of 48 hours of supplementation of various fatty acids

\begin{tabular}{|c|c|c|c|c|c|c|c|}
\hline \multirow{2}{*}{$\begin{array}{l}\text { Fatty acids } \\
\text { in PC-3 }\end{array}$} & \multicolumn{7}{|c|}{ Composition percentage (\%) } \\
\hline & Linolelaidic acid & Linoleic acid & $\gamma$-linolenic acid & Arachidonic acid & a-linolenic acid & EPA & DHA \\
\hline Control & $2.25 \pm 0.01$ & $0.14 \pm 0.01$ & $0.88 \pm 0.03$ & $1.22 \pm 0.03$ & $0.12 \pm 0 . .01$ & N.D & $0.71 \pm 0.03$ \\
\hline $\mathrm{LA}(50 \mu \mathrm{M})$ & $0.05 \pm 0.01^{* * *}$ & $0.80 \pm 0.10^{* *}$ & $0.40 \pm 0.08^{*}$ & $1.25 \pm 0.19$ & $0.09 \pm 0.02$ & $0.89 \pm 0.11^{* *}$ & $0.58 \pm 0.06$ \\
\hline LA(150 $\mu \mathrm{M})$ & $6.05 \pm 0.08^{* *}$ & $1.92 \pm 0.38^{* * *}$ & $0.42 \pm 0.14^{*}$ & $0.88 \pm 0.12^{*}$ & $5.58 \pm 0.39^{* * *}$ & $2.48 \pm 0.34^{* * *}$ & $3.02 \pm 0.26^{* *}$ \\
\hline $\mathrm{GLA}(25 \mu \mathrm{M})$ & $1.62 \pm 0.18^{*}$ & $0.19 \pm 0.08$ & $0.97 \pm 0.08$ & $15.29 \pm 2.73^{* * *}$ & $1.83 \pm 0.37^{* *}$ & N.D & $0.50 \pm 0.12$ \\
\hline $\mathrm{GLA}(50 \mu \mathrm{M})$ & $1.56 \pm 0.10^{*}$ & $0.20 \pm 0.02$ & $1.08 \pm 0.28$ & $22.24 \pm 0.31^{* * *}$ & $4.87 \pm 0.32^{* * *}$ & N.D & $0.53 \pm 0.01$ \\
\hline GLA(75 $\mu \mathrm{M})$ & $1.11 \pm 0.05^{* *}$ & $0.16 \pm 0.06$ & $0.76 \pm 0.00$ & $29.28 \pm 0.52^{* * *}$ & $10.98 \pm 0.45^{* * *}$ & N.D & $0.35 \pm 0.01^{*}$ \\
\hline $\mathrm{AA}(50 \mu \mathrm{M})$ & $1.94 \pm 0.04$ & $0.08 \pm 0.01^{* *}$ & $0.09 \pm 0.01^{* * *}$ & $14.28 \pm 0.44^{* * *}$ & $0.08 \pm 0.01$ & $0.37 \pm 0.01^{*}$ & $0.69 \pm 0.09$ \\
\hline $\mathrm{AA}(100 \mu \mathrm{M})$ & $1.88 \pm 0.04$ & $0.08 \pm 0.01^{* *}$ & $0.08 \pm 0.01^{* * *}$ & $22.20 \pm 0.63^{* * *}$ & $0.07 \pm 0.01$ & $0.46 \pm 0.01^{*}$ & $0.62 \pm 0.09$ \\
\hline $\operatorname{ALA}(50 \mu \mathrm{M})$ & $0.60 \pm 0.08^{* * *}$ & $0.45 \pm 0.08^{*}$ & $0.72 \pm 0.24$ & $1.49 \pm 0.35^{*}$ & $0.51 \pm 0.13^{*}$ & $1.98 \pm 0.42^{* *}$ & $4.83 \pm 0.68^{* *}$ \\
\hline $\mathrm{ALA}(150 \mu \mathrm{M})$ & $0.66 \pm 0.27^{* * *}$ & $1.32 \pm 0.20^{* * *}$ & $0.82 \pm 0.33$ & $1.13 \pm 0.13$ & $2.13 \pm 0.18^{* *}$ & $1.64 \pm 0.40^{* *}$ & $2.50 \pm 0.35^{* *}$ \\
\hline $\mathrm{EPA}(50 \mu \mathrm{M})$ & $2.46 \pm 0.65$ & $0.26 \pm 0.05^{*}$ & $1.35 \pm 0.12^{*}$ & $1.17 \pm 0.31$ & $0.11 \pm 0.005$ & $2.78 \pm 0.03^{* * *}$ & $9.56 \pm 0.38^{* * *}$ \\
\hline $\mathrm{EPA}(100 \mu \mathrm{M})$ & $1.79 \pm 0.13^{*}$ & $0.24 \pm 0.03^{*}$ & $1.16 \pm 0.02^{*}$ & $1.37 \pm 0.05^{*}$ & $0.14 \pm 0.03$ & $5.64 \pm 1.80^{* * *}$ & $14.11 \pm 2.57^{* * *}$ \\
\hline $\mathrm{DHA}(50 \mu \mathrm{M})$ & $1.98 \pm 0.10^{*}$ & $0.24 \pm 0.02^{*}$ & $1.08 \pm 0.03^{*}$ & $1.30 \pm 0.02$ & N.D & N.D & $11.17 \pm 1.08^{* * *}$ \\
\hline DHA $100 \mu \mathrm{M}$ & $1.88 \pm 0.04^{*}$ & $0.21 \pm 0.02^{*}$ & $0.99 \pm 0.09$ & $1.32 \pm 0.07$ & $0.11 \pm 0.02$ & $0.11 \pm 0.01^{*}$ & $19.08 \pm 0.06^{* * *}$ \\
\hline
\end{tabular}

${ }^{*} \mathrm{P}<0.05,{ }^{* * \mathrm{P}}<0.01,{ }^{* * *} \mathrm{P}<0.001$ compared to control. 

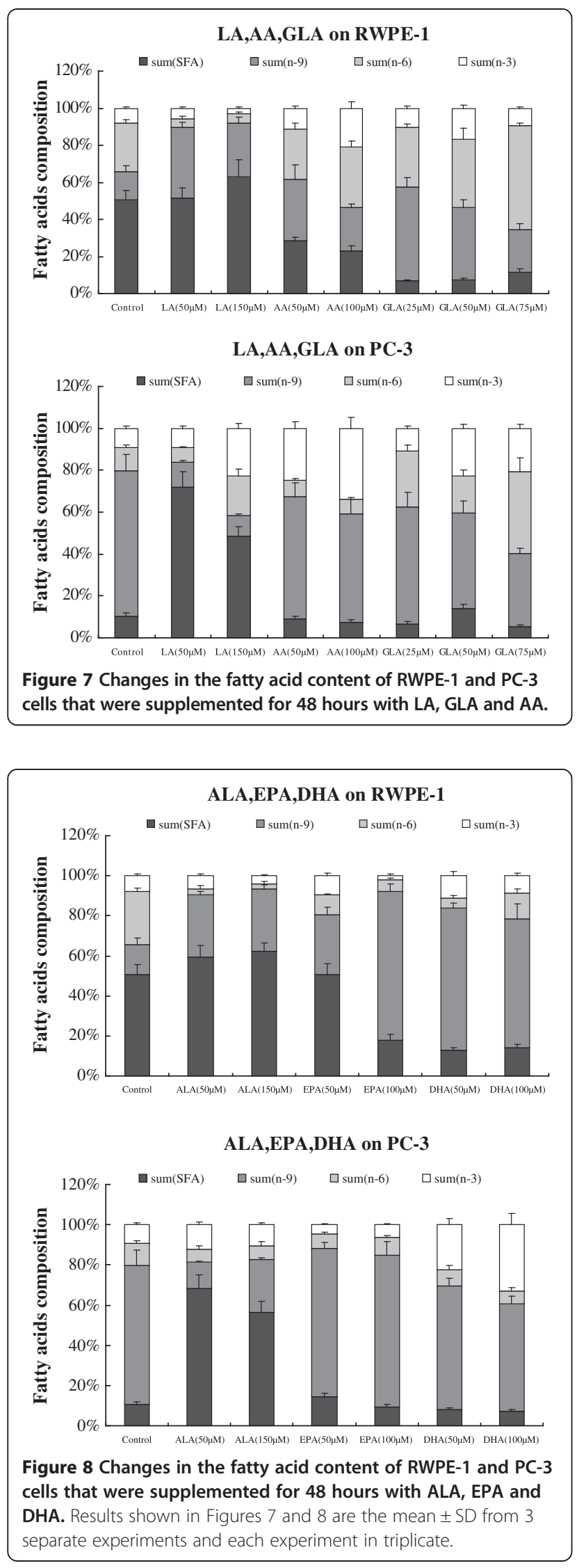

whereas their (IL-6, TNF- $\alpha, \mathrm{LXA}_{4}$ ) secretion was increased in PC-3 cells in a graded fashion with increasing doses compared with control (Figure 10 and Table 5), expect for free radicals that were decreased.

Supplementation of RWPE-1 and PC-3 cells with various doses of AA showed a general inhibition of secretion of TNF- $\alpha$ and free radical generation; while IL- 6 secretion changed little in both RWPE-1 and PC-3 cells (Figure 11 and Tables 4, 5). It is interesting to note that AA at $50 \mu \mathrm{M}$ of AA decreased $\mathrm{LXA}_{4}$ production by RWPE-1 cells while $100 \mu \mathrm{M}$ of AA enhanced $\mathrm{LXA}_{4}$ secretion. In contrast, PC-3 cells showed almost the same amount of $\mathrm{LXA}_{4}$ secretion in the presence of 50 and $100 \mu \mathrm{M}$ of AA.

The data in Figure 12 showed that ALA has produced a gradual increase in the secretion of IL- 6 , TNF- $\alpha$ and decrease in $\mathrm{LXA}_{4}$ by RWPE-1 cells and rather an opposing action on the secretion of these molecules by PC-3 cells (a decrease in IL- 6 , TNF- $\alpha, \mathrm{LXA}_{4}$, and an increase in free radical generation). In contrast to this, free radical generation by RWPE-1 cells was decreased by $50 \mu \mathrm{M}$ ALA but was maintained at the same level as that of the control $150 \mu \mathrm{M}$ ALA.

Supplementation of EPA to RWPE1 cells for $48 \mathrm{~h}$ induced a decrease in the secretion of TNF- $\alpha, \mathrm{LXA}_{4}$ and generation of free radicals with no significant change in IL-6. On the other hand, EPA induced little or no significant alterations in the secretion of IL-6, TNF- $\alpha$ and $\mathrm{LXA}_{4}$ by PC-3 cells but a slight decrease in the production of free radicals was noted at the doses tested (Figure 13 and Table 5).

When RWPE-1 and PC-3 cells were supplemented with DHA $(50 \mu \mathrm{M}$ and $100 \mu \mathrm{M})$, as shown in Figure 14, there was a reduction in the secretion of IL- 6 , TNF- $\alpha$, $\mathrm{LXA}_{4}$ and generation of free radicals by PC-3 and RWPE 1 cells except that in RWPE-1 cells there was little change in the secretion of IL-6.

\section{Discussion}

Epidemiological studies have suggested that dietary fat consumption is a major contributor to the risk of development and progression of prostate cancer. But the influence of $n-3$ and $n-6$ fatty acids on the risk of development of prostate cancer is controversial. Our present study aimed to delineate the effects of n-3 (ALA, EPA, DHA) and n- 6 fatty acids (LA, GLA, AA) on the growth of prostate cancer $\mathrm{PC}-3$ cells and its normal counterpart RWPE-1 cells and influence of these fatty acids on the generation of inflammatory cytokines, free radicals and $\mathrm{LXA}_{4}$, a potent anti-inflammatory lipid molecule. It is evident from the results that both n-3 (ALA, EPA, DHA) and n-6 PUFAs (LA, GLA, AA) suppress proliferation of both PC-3 and RWPE-1 cells, while these fatty acids at low concentrations had little influence on cell viability and even promoted their growth. RWPE-1 cells were 
Table 3 Fatty acid content and fold increase in LA, GLA, AA, ALA, EPA and DHA in RWPE-1 and PC-3 cells supplemented with these fatty acids as compared to control

\begin{tabular}{|c|c|c|c|c|}
\hline Fatty acid supplemented & RWPE-1 cells & Fold increase compared to control & PC-3 cells & Fold increase compared to control \\
\hline Control - LA & $0.38 \pm 0.09$ & - & $0.14 \pm 0.01$ & - \\
\hline LA $50 \mu \mathrm{M}$ & $1.59 \pm 0.13$ & 4.18 & $0.80 \pm 0.10$ & 5.71 \\
\hline LA $150 \mu \mathrm{M}$ & $0.52 \pm 0.18$ & 1.37 & $1.92 \pm 0.38$ & 13.71 \\
\hline Control - GLA & $0.76 \pm 0.13$ & - & $0.88 \pm 0.03$ & - \\
\hline GLA $25 \mu \mathrm{M}$ & $1.44 \pm 0.09$ & 1.89 & $0.97 \pm 0.08$ & 1.10 \\
\hline GLA $50 \mu \mathrm{M}$ & $1.01 \pm 0.13$ & 1.33 & $1.08 \pm 0.28$ & 1.23 \\
\hline GLA $75 \mu \mathrm{M}$ & $12.34 \pm 0.55$ & 17.63 & $0.76 \pm 0.01$ & $<1.0$ \\
\hline Control- AA & $0.92 \pm 0.14$ & - & $1.22 \pm 0.03$ & - \\
\hline AA $50 \mu \mathrm{M}$ & $7.01 \pm 0.74$ & 7.62 & $14.28 \pm 0.44$ & 11.70 \\
\hline AA $100 \mu \mathrm{M}$ & $10.28 \pm 0.43$ & 11.17 & $22.20 \pm 0.63$ & 18.20 \\
\hline Control- ALA & $0.47 \pm 0.09$ & - & $0.12 \pm 0.01$ & - \\
\hline ALA $50 \mu \mathrm{M}$ & $0.62 \pm 0.13$ & 1.32 & $0.51 \pm 0.13$ & 4.25 \\
\hline ALA $150 \mu \mathrm{M}$ & $0.86 \pm 0.10$ & 1.83 & $2.13 \pm 0.18$ & 17.75 \\
\hline Control- EPA & $0.86 \pm 0.13$ & - & N.D. & - \\
\hline EPA $50 \mu \mathrm{M}$ & $1.14 \pm 0.25$ & 1.33 & $2.78 \pm 0.03$ & $>2.78$ \\
\hline EPA $100 \mu \mathrm{M}$ & $4.42 \pm 0.43$ & 3.88 & $5.64 \pm 1.80$ & $>5.64$ \\
\hline Control-DHA & $2.58 \pm 0.49$ & - & $0.71 \pm 0.03$ & - \\
\hline DHA $50 \mu \mathrm{M}$ & $14.95 \pm 0.63$ & 5.79 & $11.17 \pm 1.08$ & 15.73 \\
\hline DHA $100 \mu \mathrm{M}$ & $15.35 \pm 0.08$ & 5.95 & $19.08 \pm 0.06$ & 26.87 \\
\hline
\end{tabular}

\section{LA on RWPE-1}

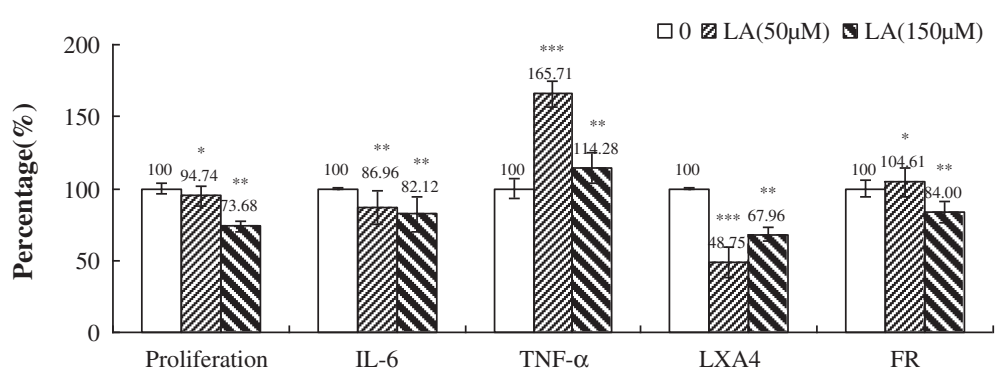

LA on PC-3

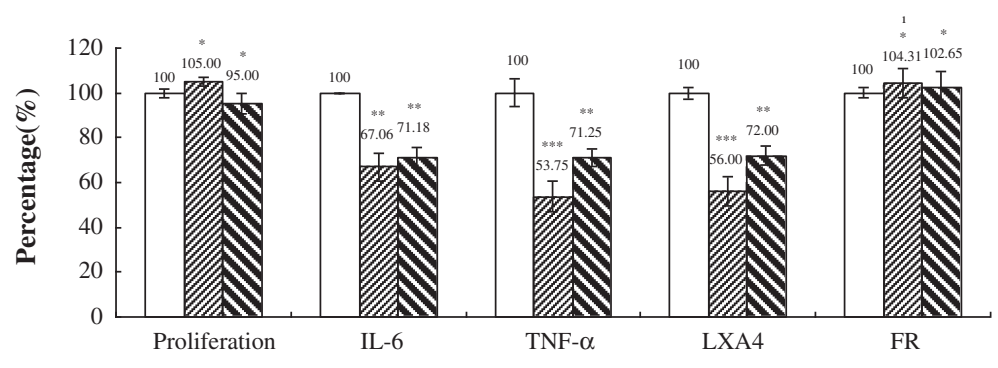

Figure 9 Effect of LA on the proliferation, cytokines, LXA4 and free radical generation by RWPE-1 and PC-3 cells in vitro. Data are presented as means \pm SEM. ${ }^{*} \mathrm{P}<0.05,{ }^{*} \mathrm{P}<0.01,{ }^{* * *} \mathrm{P}<0.001$; tTest. 


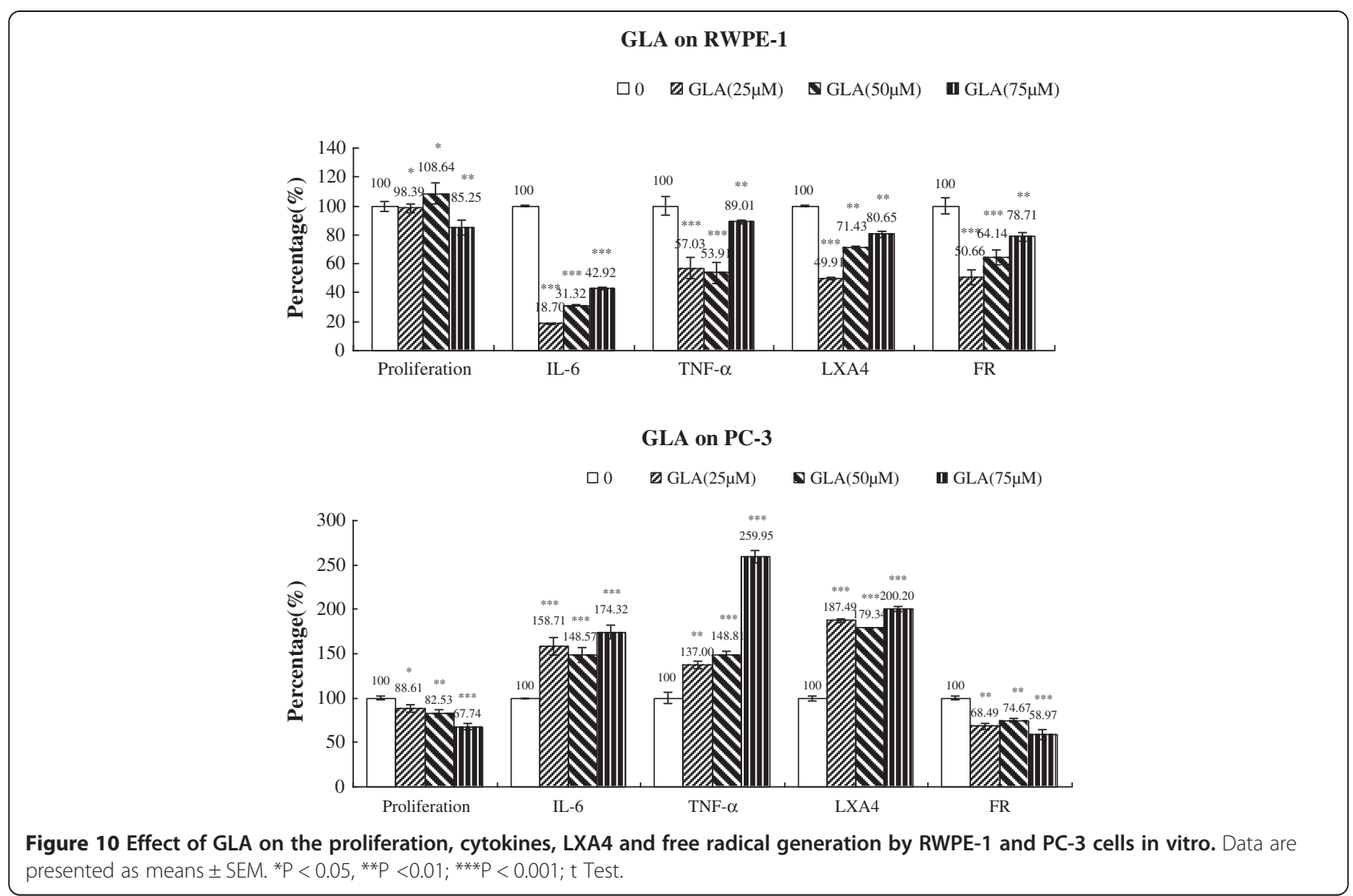

Figure 10 Effect of GLA on the proliferation, cytokines, LXA4 and free radical generation by RWPE-1 and PC-3 cells in vitro. Data are presented as means \pm SEM. ${ }^{*} \mathrm{P}<0.05,{ }^{*} \mathrm{P}<0.01 ;{ }^{* *} \mathrm{P}<0.001$; $\mathrm{t}$ Test.

\section{AA on RWPE-1}

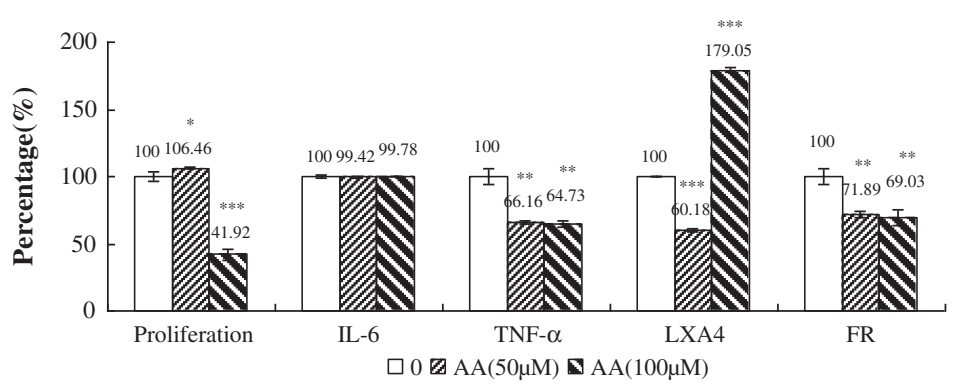

AA on PC-3

口 0 घA $(50 \mu \mathrm{M}) \quad \mathbf{D A A}(100 \mu \mathrm{M})$

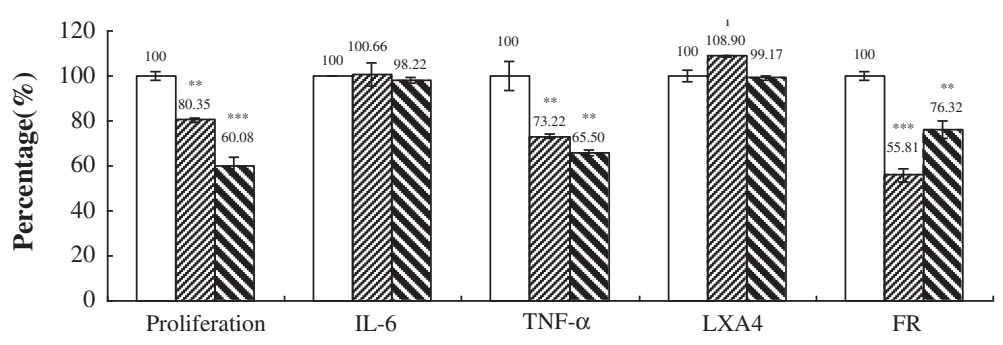

Figure 11 Effect of AA on the proliferation, cytokines, LXA4 and free radical generation by RWPE-1 and PC-3 cells in vitro. Data are presented as means \pm SEM. ${ }^{*} \mathrm{P}<0.05,{ }^{* * P}<0.01$; ${ }^{* * P}<<0.001$; $\mathrm{t}$ Test. 

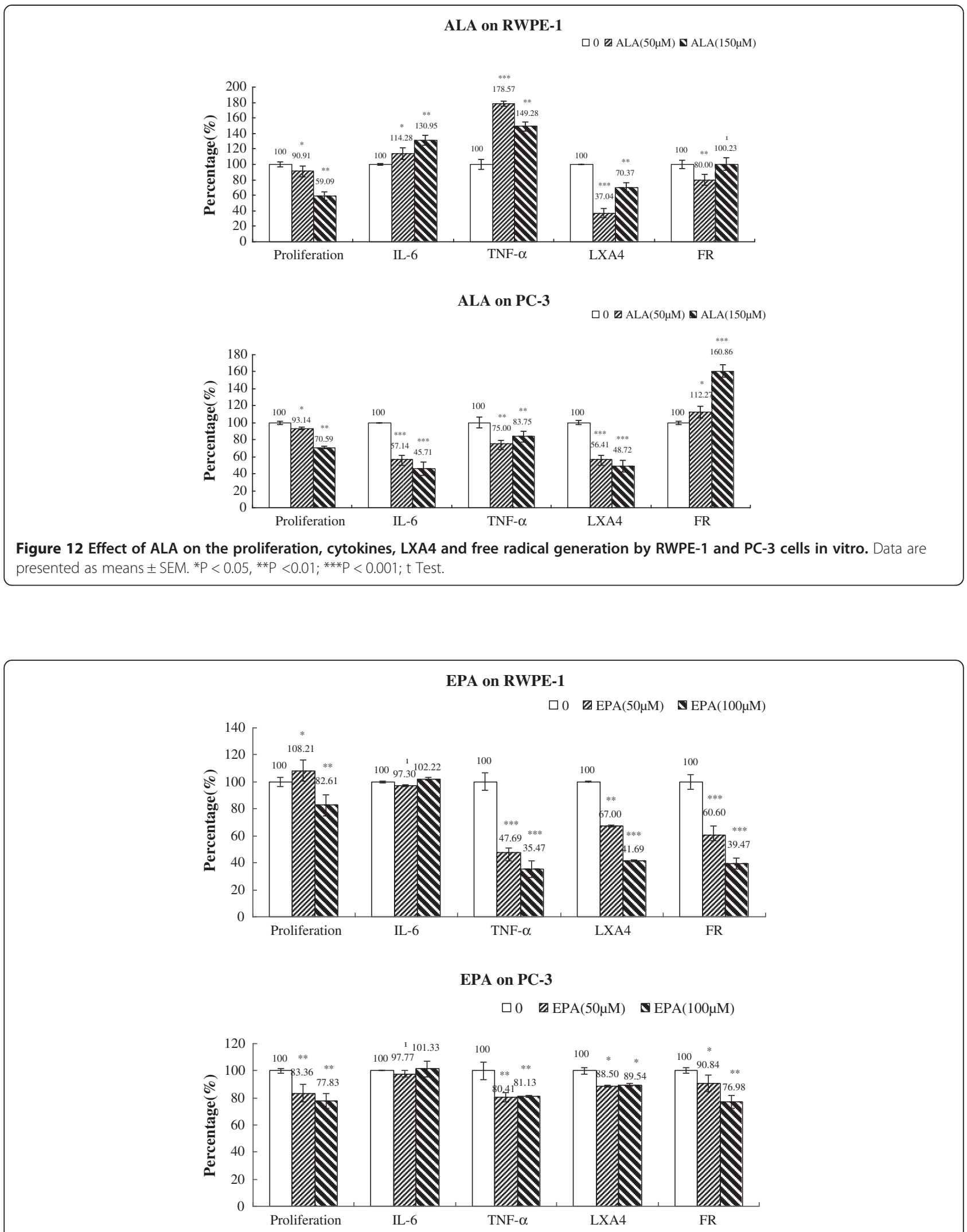

Figure 13 Effect of EPA on the proliferation, cytokines, LXA4 and free radical generation by RWPE-1 and PC-3 cells in vitro. Data are presented as means \pm SEM. ${ }^{*} \mathrm{P}<0.05$, ${ }^{* * P}<0.01 ;{ }^{* *} \mathrm{P}<0.001$; $\mathrm{t}$ Test. 


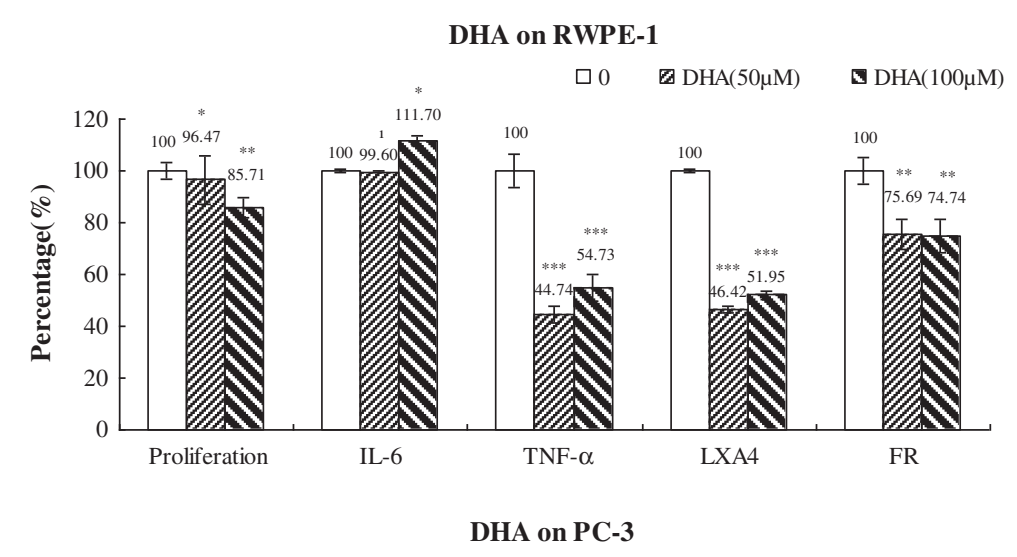

$\square 0 \square \operatorname{DHA}(50 \mu \mathrm{M}) \mathbf{\mathrm { DHA }}(100 \mu \mathrm{M})$

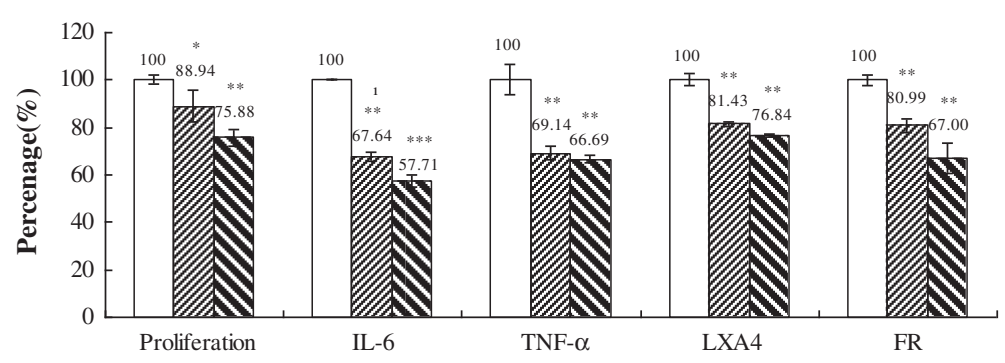

Figure 14 Effect of DHA on the proliferation, cytokines, LXA4 and free radical generation by RWPE-1 and PC-3 cells in vitro. Data are presented as means \pm SEM. ${ }^{*} P<0.05,{ }^{* * P}<0.01 ;{ }^{* * *} P<0.001 ; \mathrm{t}$ Test.

more sensitive to the growth inhibitory actions of $n-3$ (ALA, EPA, and DHA) and n-6 fatty acids (LA, GLA, AA) in comparison to their effect on PC-3 cells, implying that RWPE-1 cells are more susceptible to the cytotoxic action of fatty acids compared to PC-3 cells.
Prostate cancer develops and progresses in response to inflammation during the cancer process. This suggests that inflammation is closely linked to prostate cancer development. Several studies showed that a proinflammatory environment may be set in the prostate

Table 4 Changes seen in the survival, FR generated, and LXA, TNF-a and IL-6 secreted by RWPE-1 cells when supplemented with different doses of fatty acids for 48 hours

\begin{tabular}{|c|c|c|c|c|c|}
\hline Treatment & RWPE- $1 \%$ survival & FR generated $\%$ of control & $\mathrm{LXA}_{4}$ levels $\%$ of control & IL-6\% of control & TNF- $a \%$ of control \\
\hline Control & $100 \pm 3.49$ & $100 \pm 5.40$ & $100 \pm 0.43$ & $100 \pm 0.74$ & $100 \pm 6.43$ \\
\hline LA $50 \mu \mathrm{M}$ & $94.74 \pm 7.01^{*}$ & $104.61 \pm 10.00^{*}$ & $48.75 \pm 10.46^{* * *}$ & $86.96 \pm 11.94^{* *}$ & $165.71 \pm 8.60^{* * *}$ \\
\hline LA $150 \mu \mathrm{M}$ & $73.68 \pm 3.58^{* *}$ & $84.00 \pm 7.38^{* *}$ & $67.96 \pm 4.53^{* *}$ & $82.12 \pm 11.94^{* *}$ & $114.28 \pm 10.77^{* *}$ \\
\hline GLA $25 \mu \mathrm{M}$ & $98.39 \pm 2.94^{*}$ & $50.66 \pm 4.80^{* * *}$ & $49.91 \pm 0.70^{* * *}$ & $18.70 \pm 0.42^{* * *}$ & $57.03 \pm 7.18^{* * *}$ \\
\hline GLA $50 \mu \mathrm{M}$ & $108.64 \pm 7.30^{*}$ & $64.14 \pm 5.10^{* * *}$ & $71.43 \pm 0.79^{* *}$ & $31.32 \pm 0.51^{* * *}$ & $53.91 \pm 7.47^{* * *}$ \\
\hline GLA $75 \mu \mathrm{M}$ & $85.25 \pm 4.95^{* *}$ & $78.71 \pm 2.77^{* *}$ & $80.65 \pm 2.17^{* *}$ & $42.92 \pm 1.17^{* * *}$ & $89.01 \pm 0.97^{* *}$ \\
\hline AA $50 \mu \mathrm{M}$ & $106.46 \pm 0.69^{*}$ & $71.89 \pm 2.17^{* *}$ & $60.18 \pm 0.79^{* * *}$ & $99.42 \pm 0.30$ & $66.16 \pm 0.94^{* *}$ \\
\hline AA $100 \mu \mathrm{M}$ & $41.92 \pm 3.93^{* * *}$ & $69.03 \pm 5.77^{* *}$ & $179.05 \pm 1.95^{* * *}$ & $99.78 \pm 0.23$ & $64.73 \pm 1.83^{* *}$ \\
\hline ALA $50 \mu \mathrm{M}$ & $90.91 \pm 7.35^{*}$ & $80.00 \pm 7.34^{* *}$ & $37.04 \pm 6.00^{* * *}$ & $114.28 \pm 7.49^{*}$ & $178.57 \pm 2.85^{* * *}$ \\
\hline 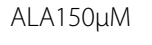 & $59.09 \pm 5.44^{* *}$ & $100.23 \pm 8.08$ & $70.37 \pm 6.00^{* *}$ & $130.95 \pm 6.43^{* *}$ & $149.28 \pm 5.77^{* *}$ \\
\hline EPA $50 \mu \mathrm{M}$ & $108.2 \pm 7.74^{*}$ & $60.60 \pm 6.50^{* * *}$ & $67.00 \pm 1.15^{* *}$ & $97.30 \pm 0.57$ & $47.69 \pm 3.03^{* * *}$ \\
\hline EPA $100 \mu \mathrm{M}$ & $82.61 \pm 7.85^{* *}$ & $39.47 \pm 4.32^{* * *}$ & $41.69 \pm 0.64^{* * *}$ & $102.22 \pm 0.93$ & $35.47 \pm 6.16^{* * *}$ \\
\hline DHA $50 \mu \mathrm{M}$ & $96.47 \pm 9.31^{*}$ & $75.69 \pm 5.70^{* *}$ & $46.42 \pm 1.06^{* * *}$ & $99.60 \pm 0.44$ & $44.74 \pm 3.31^{* * *}$ \\
\hline 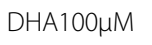 & $85.71 \pm 3.97^{* *}$ & $74.74 \pm 6.44^{* *}$ & $51.95 \pm 1.69^{* * *}$ & $111.70 \pm 2.09^{*}$ & $54.73 \pm 5.25^{* * *}$ \\
\hline
\end{tabular}

${ }^{*} \mathrm{P}<0.05,{ }^{* * P}<0.01,{ }^{* * * P}<0.001$ compared to control. 
Table 5 Changes seen in the survival, FR generated, and LXA, TNF- $\alpha$ and IL- 6 secreted by PC-3 cells when supplemented with different doses of fatty acids for $\mathbf{4 8}$ hours

\begin{tabular}{|c|c|c|c|c|c|}
\hline Treatment & PC-3\% survival & FR generated $\%$ of control & LXA4 levels\% of control & IL-6\% of control & TNF- $a \%$ of control \\
\hline Control & $100 \pm 1.86$ & $100 \pm 2.09$ & $100 \pm 2.60$ & $100 \pm 0.07$ & $100 \pm 6.34$ \\
\hline LA $50 \mu \mathrm{M}$ & $105.00 \pm 1.81^{*}$ & $104.31 \pm 6.33^{*}$ & $56.00 \pm 6.61^{* * *}$ & $67.06 \pm 6.11^{* *}$ & $53.75 \pm 6.67^{* * *}$ \\
\hline LA $150 \mu \mathrm{M}$ & $95.00 \pm 4.62^{*}$ & $102.65 \pm 6.77^{*}$ & $72.00 \pm 4.00^{* *}$ & $71.18 \pm 4.58^{* *}$ & $71.25 \pm 3.97^{* *}$ \\
\hline GLA $25 \mu \mathrm{M}$ & $88.61 \pm 4.39^{*}$ & $68.49 \pm 3.35^{* *}$ & $187.49 \pm 2.11^{* * *}$ & $158.71 \pm 9.66^{* * *}$ & $137.00 \pm 3.94^{* *}$ \\
\hline GLA $50 \mu \mathrm{M}$ & $82.53 \pm 3.72^{* *}$ & $74.67 \pm 2.34^{* *}$ & $179.34 \pm 0.79^{* * *}$ & $148.57 \pm 8.14^{* * *}$ & $148.81 \pm 4.64^{* * *}$ \\
\hline GLA $75 \mu \mathrm{M}$ & $67.74 \pm 3.81^{* * *}$ & $58.97 \pm 5.11^{* * *}$ & $200.20 \pm 2.94^{* * *}$ & $174.32 \pm 7.32^{* * *}$ & $259.95 \pm 6.95^{* * *}$ \\
\hline AA $50 \mu \mathrm{M}$ & $80.35 \pm 1.21^{* *}$ & $55.81 \pm 2.99^{* * *}$ & $108.90 \pm 0.39^{*}$ & $100.66 \pm 5.24$ & $73.22 \pm 0.91^{* *}$ \\
\hline AA $100 \mu \mathrm{M}$ & $60.08 \pm 4.04^{* * *}$ & $76.32 \pm 3.80^{* *}$ & $99.17 \pm 1.07$ & $98.22 \pm 1.32$ & $65.50 \pm 1.28^{* *}$ \\
\hline ALA $50 \mu \mathrm{M}$ & $93.14 \pm 1.66^{*}$ & $112.27 \pm 6.82^{*}$ & $56.41 \pm 5.44^{* * *}$ & $57.14 \pm 4.58^{* * *}$ & $75.00 \pm 3.90^{* *}$ \\
\hline 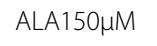 & $70.59 \pm 1.51^{* *}$ & $160.86 \pm 7.10^{* * *}$ & $48.72 \pm 6.92^{* * *}$ & $45.71 \pm 7.70^{* * *}$ & $83.75 \pm 6.54^{* *}$ \\
\hline $\mathrm{EPA} 50 \mu \mathrm{M}$ & $83.36 \pm 6.65^{* *}$ & $90.84 \pm 6.30^{*}$ & $88.50 \pm 0.75^{*}$ & $97.77 \pm 2.13$ & $80.41 \pm 3.29^{* *}$ \\
\hline EPA $100 \mu \mathrm{M}$ & $77.83 \pm 5.55^{* *}$ & $76.98 \pm 4.97^{* *}$ & $89.54 \pm 1.22^{*}$ & $101.33 \pm 5.59$ & $81.13 \pm 1.00^{* *}$ \\
\hline DHA $50 \mu \mathrm{M}$ & $88.94 \pm 6.91^{*}$ & $80.99 \pm 2.88^{* *}$ & $81.43 \pm 1.09^{* *}$ & $67.64 \pm 1.95^{* *}$ & $69.14 \pm 2.85^{* *}$ \\
\hline 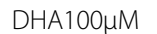 & $75.88 \pm 3.55^{* *}$ & $67.00 \pm 6.24^{* *}$ & $76.84 \pm 0.69 * *$ & $57.71 \pm 2.78^{* * *}$ & $66.69 \pm 1.60^{* *}$ \\
\hline
\end{tabular}

${ }^{*} \mathrm{P}<0.05,{ }^{* *} \mathrm{P}<0.01,{ }^{* * *} \mathrm{P}<0.001$ compared to control.

gland tissue when the balance between pro- and antiinflammatory PUFAs (n-6 PUFAs vs n-3 PUFAs) is tilted more towards the pro-inflammatory (n-6 PUFAs) fatty acids. N-3 PUFAs: ALA, EPA and DHA have the ability to displace AA from the cell membrane phospholipids and suppress the production of pro-inflammatory eicosanoids. But, it needs to be noted that AA not only forms precursor to pro-inflammatory prostaglandins, leukotrienes and thromboxanes but can also give rise to $\mathrm{LXA}_{4}$, a potent anti-inflammatory compound. Since cancer is associated with low-grade systemic and local inflammation, we evaluated whether the growth inhibitory actions shown by various fatty acids could be attributed to their ability to alter the formation of $\mathrm{LXA}_{4}$ both in the normal and cancer cells. The results of the present study showed that LA, ALA, EPA and DHA and LA GLA, AA, EPA and DHA decreased secretion of $\mathrm{LXA}_{4}$ by PC-3 cells and RWPE-1 cells respectively, while GLA enhanced and AA had very little effect on the secretion of $\mathrm{LXA}_{4}$ in PC-3 cells. These results suggest that, in general, most of the $n-3$ and $n-6$ fatty acids decrease $\mathrm{LXA}_{4}$ secretion by both normal and tumor cells with the exception of GLA and AA. These results underscore the complex nature of interaction among various PUFAs (both $n-3$ and n-6 PUFAs), their pro- and anti-inflammatory products (such as prostaglandins, leukotrienes and thromboxanes and lipoxins), local and systemic inflammatory process and the growth of prostate cancer cells.

IL-6 and TNF- $\alpha$ are pleiotropic cytokines that function as autocrine or paracrine growth factors, which are secreted by normal prostate epithelial and cancer cells. Androgen-refractory prostate cancer cells have been shown to produce detectable amounts of IL-6 [26]. N-3 and n-6 PUFAs modulate inflammation by influencing the production of IL- 6 and TNF- $\alpha$ [27-29]. In the present study, n-6 fatty acids (LA, GLA) inhibited the production of IL- 6 by RWPE- 1 cells, while ALA, EPA and DHA did not suppress IL-6 secretion, while ALA enhanced IL-6 secretion (ALA > DHA > EPA). On the other hand, LA decreased but GLA increased IL-6 secretion by PC-3 cells, with no change in IL- 6 secretion by AA. TNF- $\alpha$ secretion was increased by LA, but decreased by GLA and AA by RWPE-1 cells, whereas ALA increased but both EPA and DHA decreased the same. In PC-3 cells, LA and AA decreased TNF- $\alpha$ secretion whereas all the three n-3 fatty acids (ALA, EPA and DHA) decreased it by PC-3 cells. Thus, GLA inhibited and ALA enhanced the secretion of IL- 6 and TNF- $\alpha$ by RWPE- 1 cells, which showed the opposite results in PC-3 cells. However, all other fatty acids (except for LA on RWPE-1) suppressed the secretion of TNF- $\alpha$ at all the doses tested by both RWPE- 1 and PC-3 cells, indicating that, in general, both n-3 and n-6 fatty acids inhibit the secretion of TNF- $\alpha$ by both normal and tumor cells in vitro. These results are interesting in the light of the controversy as to the role of n-6 PUFAs on tumor development since in the present study it was noted that LA and AA inhibited while GLA enhanced TNF- $\alpha$ secretion. These results suggest that the local concentration of n-6 PUFAs can modulate the secretion of TNF- $\alpha$ that, in turn, influence the local inflammatory process 
and consequently the process of carcinogenesis and growth of the tumor cells depending on the ratio among various n-6 PUFAs: LA, GLA and AA.

LA is the precursor for AA, which can be metabolized to pro-inflammatory and anti-inflammatory products whereas ALA is the precursor of EPA that can displace AA which may result in decreased production of pro-inflammatory eicosanoids form AA. Thus, supplementations with GLA, ALA and/or EPA modulate the inflammatory response(s). However, the results of our current study are inconsistent with what was mentioned above, which suggest that there could exist other unidentified pathways of lipid metabolism that may participate in the process of carcinogenesis and tumor cell growth. It is also likely that influence of various n-3 and n-6 lipids on the inflammatory response and process could be different in different types of cells.

It is known that supplemented fatty acids are incorporated into the cell membrane lipid pool that may influence secretion of various cytokines, free radicals and growth characteristics. Hence, we performed fatty acid analysis of both RWPE-1 and PC-3 cells that were supplemented with various fatty acids. As expected, there were significant changes in the fatty acid composition of both RWPE-1 and PC-3 cells that were supplemented with various fatty acids. It is evident from these results that supplementation of PUFAs to both RWPE-1 and PC-3 cells produced a significant increase in the respective fatty acids in both types of cells. For instance, supplementation of RWPE-1 and PC-3 cells with LA $50 \mu \mathrm{M}$ and $150 \mu \mathrm{M}$ produced approximately a 5 -fold and 1.4 fold increase in LA content of RWPE-1 cells and a 5-fold and 8 -fold increase in LA content of PC-3 cells respectively compared to respective controls. Similar significant increase in the levels of supplemented fatty acids (Viz., GLA, AA, ALA, EPA and DHA) in RWPE-1 and PC-3 cells was noted. One significant observation when the incorporation of supplemented fatty acids by RWPE-1 and PC-3 cells noted was that all the supplemented fatty acids were not incorporated to the same extent by these cells. Certain fatty acids were incorporated by RWPE-1 and PC-3 cells to a much larger extent compared to others. This is evident from the data shown in Table 2. It can be seen from the results shown in Table 2 that supplementation of fatty acids produced anywhere from 1.3 fold to 26 -fold increase in the fatty acid content of the specific fatty acid supplemented.

Furthermore, supplementation ALA (both 50 and $150 \mu \mathrm{M})$ enhanced the content of ALA and EPA but not of DHA; EPA enhanced the content of both EPA and DHA; whereas DHA increased the content of only DHA in RWPE-1 cells significantly. On the other hand, RWPE-1 cells when were incubated with LA, a significant increase in the content of LA and GLA occurred with no change in that of AA; GLA induced a significant increase of GLA and AA; whereas supplementation of AA increased those of LA, GLA and AA. These results suggest that to certain extent, the supplemented fatty acids such as ALA, EPA and LA, and AA are metabolized to their long - chain metabolites namely ALA to EPA and DHA; EPA to DHA; LA to GLA and GLA to AA. The surprising observation that supplementation of AA to RWPE-1 cells led to an increase in LA and GLA content raises the interesting possibility that there is some amount of retroconversion of AA to GLA and LA. It is interesting to note that supplementation of AA to RWPE-1 cells led to an increase in their content of ALA, EPA and DHA (especially when they were supplemented with $100 \mu \mathrm{M}$ ) from $0.47 \pm 0.09$ in control to $1.60 \pm 0.22$ of ALA; from $0.86 \pm 0.13$ to $10.63 \pm 1.27$ of EPA and from $2.58 \pm 0.49$ to $9.30 \pm 1.68$ of DHA suggesting that a close interaction exists between the metabolism of n-3 and n- 6 fatty acids, though such dramatic changes in the content of n- 6 fatty acids was not noted when RWPE-1 cells were supplemented with n-3 fatty acids ALA, EPA and DHA (see Table 1).

In a similar fashion, PC-3 cells supplemented with LA (especially with $150 \mu \mathrm{M}$ ) showed an increase in ALA, EPA and DHA with a concomitant significance increase in LA; while supplementation with GLA and AA (at all the doses tested) produced a significant increase in their content of AA (Table 2), suggesting that GLA is being elongated and desaturated to AA. GLA supplementation enhanced the ALA content of PC-3 cells with little or no change in EPA and DHA and if at all there is any change a decrease in their DHA content was noted, suggesting that GLA is able to block the conversion of ALA to its long-chain metabolites EPA and DHA that could have enhanced its (PC-3 cells) ALA content (see Table 2). Supplementation of PC-3 cells with ALA, EPA and DHA enhanced their content of EPA and DHA and of only DHA in DHA-supplemented cells suggesting that there is no retroconversion of DHA to EPA in the latter. Increased levels of EPA and DHA in ALA-supplemented PC-3 cells indicate that ALA is being elongated and desaturated to EPA and DHA in these cells. These results indicate that the way $n-3$ and n- 6 fatty acids are handled by RWPE-1 and PC-3 cells are quite different.

In conclusion, our data suggest that there are significant differences in the way RWPE- 1 and PC-3 cells metabolize n-6 and n-3 fatty acids, their ability to secrete inflammatory cytokines in the presence of various fatty acids and de novo fatty acid synthetic pathways. Though we could not identify the precise mechanism by which $n-3$ and n- 6 fatty acids are able to bring about their cell killing effect since none of the indices studied (free radicals generated, changes in the levels of $\mathrm{LXA}_{4}$, IL-6 and TNF- $\alpha$ secreted) showed any direct correlation among tumor cell survival and the indices studied, it is likely 
that several mechanism(s) may be at play that include: generation of significant amounts of free radicals, formation of higher amounts of lipid peroxides in PUFA-supplemented cells, changes in the formation and secretion of anti-inflammatory cytokines and the response of cells to the growth enhancing potential of these cytokines, and the ability of these cells to secrete anti-inflammatory bioactive lipids such as lipoxin $\mathrm{A}_{4}$. Obviously, more in-depth studies are needed to understand the mechanism(s) involved in the cytotoxic action of n-3 and $n-6$ fatty acids on prostate cancer cells and prostate normal cells.

\section{Competing interests}

The authors declare that they have no competing interests.

\section{Authors' contributions}

SRS and UND conceived the idea and designed the experiments. HZM and YZS performed the experiments and drafted the manuscript. JHS and FZ participated in the design of the study and performed the statistical analysis. SRS and UND performed the interpretation of the data. All authors read and approved the final manuscript.

\section{Acknowledgements}

UND is in receipt of Ramalingaswami Fellowship of the Department of Biotechnology, New Delhi during the tenure of this study.

\section{Author details}

'Department of Urology, The First Affiliated Hospital, Zhejiang University, Hangzhou 310003, China. ${ }^{2}$ Department of Food Science and Nutrition, School of Biosystems Engineering \& Food Science, Zhejiang University, Hangzhou 310058, China. ${ }^{3}$ School of Medicine, Tongji University, Shanghai 200092, China. ${ }^{4}$ UND Life Sciences, 2020 S 360th St, K-202, Federal Way, WA 98003, USA. ${ }^{5}$ School of Biotechnology, Jawaharlal Nehru Technological University, Kakinada 533 003, India. ${ }^{6}$ Department of Medicine, GVP Hospital and Bio-Science Research Centre, Campus of GVP College of Engineering, Visakhapatnam 530 048, India.

Received: 17 July 2013 Accepted: 25 October 2013

Published: 29 October 2013

\section{References}

1. American Cancer Society: Cancer Facts \& Figures 2009. Atlanta (GA): American Cancer Society; 2009

2. Sfanos KS, De Marzo AM: Prostate cancer and inflammation: the evidence. Histopathology 2012, 60:199-215.

3. Wynder EL, Mabuchi K, Whitmore WF Jr: Epidemiology of cancer of the prostate. Cancer 1971, 28:344-360.

4. Berquin IM, Min Y, Wu R, et al: Modulation of prostate cancer genetic risk by omega-3 and omega-6 fatty acids. J Clin Invest 2007, 117:1866-1875.

5. Leitzmann MF, Stampfer MJ, Michaud DS: Dietary intake of $n-3$ and $n-6$ fatty acids and the risk of prostate cancer. Am J Clin Nutr 2004, 80:204-216.

6. Williamsa $C D$, Whitley $B M$, Hoyod $C$, et al: $A$ high ratio of dietary $n-6 / n-3$ polyunsaturated fatty acids is associated with increased risk of prostate cancer. Nutr Res 2011, 31:1-8.

7. Niclis C, Diaz MD, Eynard AR, et al: Dietary habits and prostate cancer prevention: a review of observational studies by focusing on South America. Nutr Cancer 2012, 64:23-33.

8. Croft $K D$, Beilin $U$, Vandongen $R$, et al: Dietary modification of fatty acid and prostaglandin synthesis in the rat: effect of variations in the level of dietary fat. Biochim Biophys Acta 1984, 795:196-207.

9. Rose DP: Dietary fatty acids and prevention of hormone-responsive cancer. Proc Soc Exp Biol Med 1997, 216:224-233.

10. Berquin IM, Edwards IJ, Kridel SJ, Yong Q, Chen YQ: Polyunsaturated fatty acid metabolism in prostate cancer. Cancer Metastasis Rev 2011, 30:295-309.

11. Das UN: Essential fatty acids and their metabolites as modulators of stem cell biology with reference to inflammation, cancer, and metastasis. Cancer Metastasis Rev 2011, 30:311-324.
12. Santos CR, Schulze A: Lipid metabolism in cancer. FEBS J 2012, 279:2610-2623.

13. Das UN: Essential fatty acids enhance free radical generation and lipid peroxidation to induce apoptosis of tumor cells. Clin Lipidol 2011, 6:463-489.

14. Malagarie-Cazenave S, Olea-Herrero N, Vara D, et al: The vanilloid capsaicin induces IL-6 secretion in prostate PC-3 cancer cells. Cytokine 2011, 54:330-337.

15. Chung TDK, Yu JJ, Spiotto MT, et al: Characterization of the role of IL-6 in the progression of prostate cancer. Prostate 1999, 38:199-207.

16. Royuela M, Ricote M, Parsons MS, et al: Immunohistochemical analysis of IL-6 family of cytokines and their receptors in benign, hyperplastic and malignant human prostate. J Pathol 2004, 202:41-49.

17. Serhan CN, Chiang N, Van Dyke TE: Resolving inflammation: dual antiinflammatory and proresolution lipid mediators. Nat Rev Immunol 2008, 8:349-361

18. Das UN: Molecular Basis of Health and Disease. New York: Springer: 2011.

19. Das UN: Tumoricidal action of cis-unsaturated fatty acids and its relationship to free radicals and lipid peroxidation. Cancer Lett 1991, 56:235-243.

20. Begin ME, Das UN, Ells G: Cytotoxic effects of essential fatty acids (EFA) in mixed cultures of normal and malignant human cells. Prog Lipid Res 1986, 25:573-576.

21. Madhavi N, Das UN: Effect of $n-6$ and $n-3$ fatty acids on the survival of vincristine sensitive and resistant human cervical carcinoma cells in vitro. Cancer Lett 1994, 84:31-41.

22. Das UN, Begin ME, Ells G, Horrobin DF: Uptake and distribution of cisunsaturated fatty acids and their effect on free radical generation in normal and tumor cells in vitro. Free Radic Biol Med 1987, 3:9-16.

23. Yang J, Yu H, Sun S, Zhang L, Das UN, Ruan H, He G, Shen S: Mechanism of free $\mathrm{Zn}(2+)$ enhancing inhibitory effects of EGCG on the growth of PC-3 cells: interactions with mitochondria. Biol Trace Elem Res 2009, 131:298-310.

24. Maldonado-Pérez $D$, Golightly E, Denison FC, et al: A role for lipoxin $A_{4}$ as anti-inflammatory and proresolution mediator in human parturition. FASEB J 2011, 25:569-575.

25. Seppänen-Laakso T, Laakso I, Hiltunen R: Analysis of fatty acids by gas chromatography, and its relevance to research on health and nutrition. Anal Chim Acta 2002, 465:39-62.

26. Twillie $D A$, Eisenbserger $M A$, Carducci $M A$, et al: Interleukin 6: a candidate mediator of human prostate cancer morbidity. Urology 1995, 45:542-549.

27. Chavali SR, Zhong WW, Forse RA: Dietary a-linolenic acid increases TNF-a and decreases IL-6, IL-10 in response to LPS: effects of sesamin on the $\Delta-5$ desaturation of $\omega-6$ and $\omega-3$ fatty acids in mice. Prostaglandins Leukot Essent Fatty Acids 1998, 58:185-191.

28. Kumar SG, Das UN: Effect of prostaglandins and their precursors on the proliferation of human lymphocytes and their secretion of tumor necrosis factor and various interleukins. Prostaglandins Leukot Essent Fatty Acids 1994, 50:331-334.

29. Das UN: Beneficial effect of eicosapentaenoic acid and docosahexaenoic acid in the management of systemic lupus erythematosus and its relationship to the cytokine network. Prostaglandins Leukot Essent Fatty Acids 1994, 51:207-213.

doi:10.1186/1476-511X-12-160

Cite this article as: Meng et al: Effect of $n-3$ and $n-6$ unsaturated fatty acids on prostate cancer (PC-3) and prostate epithelial (RWPE-1) cells in vitro. Lipids in Health and Disease 2013 12:160. 